\title{
User Behavior Tendencies on Data Collections in a Digital Library
}

\author{
Michalis Sfakakis ${ }^{1}$ and Sarantos Kapidakis ${ }^{2}$ \\ ${ }^{1}$ National Documentation Centre / National Hellenic Research Foundation, \\ 48 Vas. Constantinou, GR-11635 Athens, Greece \\ msfaka@ekt.gr \\ ${ }^{2}$ Archive and Library Sciences Department / Ionian University, \\ Plateia Eleftherias, Paleo Anaktoro, Corfu 49100, Greece \\ sarantoseionio.gr
}

\begin{abstract}
We compare the usage of a Digital Library with many different categories of collections, by examining its log files for a period of twenty months, and we conclude that the access points that the users mostly refer to, depend heavily on the type of content of the collection, the detail of the existing metadata and the target user group. We also found that most users tend to use simple query structures (e.g. only one search term) and very few and primitive operations to accomplish their request. Furthermore, as they get more experienced, they reduce the number of operations in their sessions.
\end{abstract}

\section{Introduction}

The evolution of Digital Libraries attends great interest by researchers in a variety of disciplines during the last years. Especially the study to understand and evaluate their usage has become a centric point in a number of Digital Library projects ([9], [10]) and specifies a number of critical factors during the design, creation and development process of a Digital Library ([12]).

Depending on the study and its use, a number of appropriate qualitative or quantitative methods exist ([3], [4]) to accomplish it. An unobtrusive way to study and evaluate user behavior is the Transaction Log Analysis. Although log analysis is used as an effective method to assess how users actually interact with a working Digital Library, this method hardly provides any information about the users' reasons behind their specific behavior - which is also very difficult to extract - and it is lack of giving information on their intentions. The accuracy of this quantitative method heavily depends on the detail of the information logged (automatically by the system), the period of time used to log the information, the usage and the number of the performed transactions during the log period. Such data are not usually publicly available (especially in detail) because of privacy constraints. For these reasons and due to that large Digital Libraries have recently started developing, only a few studies exist based on this technique ([5], [7], [8], [11]).

In this work, based on the logged information, we study and evaluate the behavioral tendencies of different user groups on a variety of collections in the Digital Library of the Hellenic National Documentation Centre $(N D C)$. The Digital Library of 
NDC (http://theses.ndc.gr) is one of the most significant in Greece and consists of more than ten collections of diverse types. Most of these collections are unique world wide with internationally interesting content. In particular, the "Hellenic Ph.D. Dissertations Thesis" collection is part of the international Networked Digital Library of Theses and Dissertation Initiative ([2]). The Digital Library of NDC is targeted to a number of diverse types of user groups (e.g. students, researchers, professionals, librarians, etc.), mainly in Greece, from a variety of scientific domains.

In the following section we describe the goal and the methodology of this study. We also describe the collections, their characteristics, the targeted user groups they refer to and the functionality of the available operations by the system. Then we present some our most important observations from the operation distribution, the Access Points usage and how users accomplish their requests, together with our interpretation and conclusions. Finally we present a number of interesting issues arrived from this work for further evaluation and research.

\section{Purpose and Methodology of the Study}

The goal of this study is to compare and evaluate the differences on the usage among data collections, based on the collection content type, metadata and characteristics and also to approach the way diverse kinds of users accomplish their requests.

For a period of twenty months, we logged the operations performed by the users on the content of ten different collections of a Digital Library, using a specific web based retrieval system. Considering the content type (e.g. $\mathrm{PhD}$ theses, articles in a specific scientific area, Books and Periodicals Union catalogues etc.), the structure and the metadata quality of the collection (specificity, completeness of fields, syntactic correctness and consistency as implemented by authority files [6]), plus the target group they refer to, we selected the eight most used ones and classified them into four categories:

1. Hellenic Ph.D. Dissertations Thesis $(C 1)$ with bilingual metadata and Hellenic Scientific Libraries Serials Union Catalogue (C2), with a medium consistency level, targeted to diverse kinds of scientific user groups (e.g. students, researchers etc.) from all scientific domains.

2. Medical Bibliography - Hippocrates (C3) and Social Science Bibliography GLAFKA (C4), with simple metadata structure and a low consistency level, targeted to a specific scientific user group (e.g. doctors, sociologists and researchers).

3. Hellenic Archaeological Records - grARGOS(C5) and International Archaeological Records - intARGOS $(C 6)$, including library material with diverse types of data and a good consistency level, targeted to a specific scientific user group (e.g. researchers on Archaeology).

4. Hellenic School Libraries (C7) and Hellenic Public Libraries Union Catalogue (C8), union catalogs for library materials from many domains and a very good consistency level, targeted to librarians.

All the above collections are structured using the UNIMARC format with almost the same level of quality attributes specificity, completeness of fields, syntactic correctness, but a different level of the quality consistency attribute as described in every category. From their 300,000 metadata records there are links giving online access to 
14,000 digitized documents composed of 2,000,000 scanned pages and few other object formats.

The web-based retrieval system that we monitored is implementing a Z39.50 client and connects to a Z39.50 server. The users start their sessions by selecting and connecting to a collection. After connecting to a collection, a user may express his search request or browse specific Access Points (e.g. extracts information about metadata indexing - the terminology used for naming them is the one of the Z39.50 attribute set bib-1 as defined in [1]) and then to retrieve (present) the documents. In some cases, there is the ability to further access the object (document) that includes the full text, mostly in scanned images. There are seventeen available Access Points and the "search" operation supports Boolean combinations of them. When the user browse the terms from a specific Access Point, the system permits either to select a term in order to use it in a "search" operation or to retrieve ("present") the corresponding documents for display or further processing (searching and retrieving). From the more advanced searching techniques, the system also supports Boolean search combination of previously issued result sets, Search History and Selection of specific records from individual result sets.

During the study covering period, no major modifications occurred on the two basic components of the Digital Library, the collections and the retrieval system. Fig. 1 shows the number of sessions and operations for all collections on a monthly basis, where the operations have been divided by five, to be visible on the same scale. •he number of operations, sessions and users increased while maintaining an annual periodic variation, and the number of sessions and operations seem to have the same transitions.

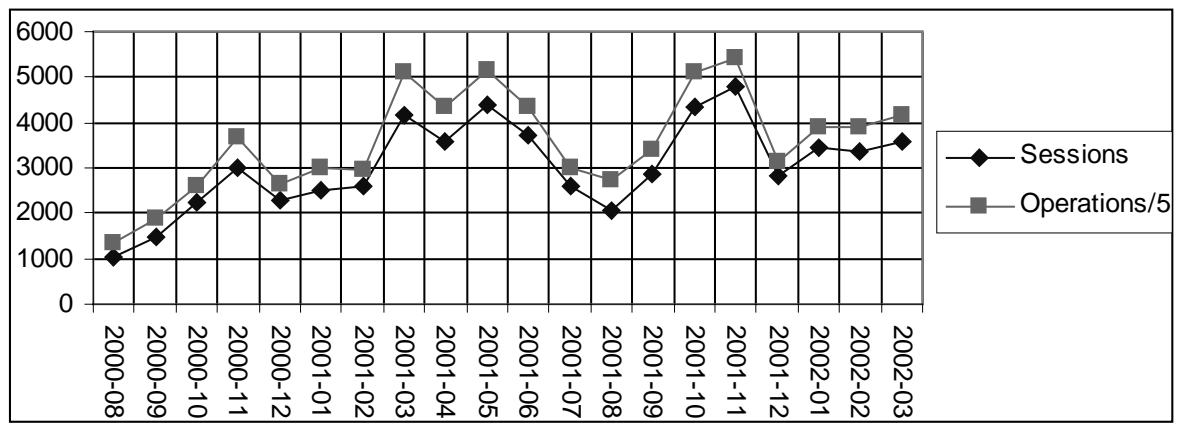

Fig. 1. Number of Sessions and Operations/5 per month

From August 2000 till March 2002, the study covering period, we recorded 490,042 operations from all the collections of the Digital Library to process and evaluate. From this set of operations we select only those that concern the eight selected collections and finally, in order to be more accurate in our study, we exclude all operations that do not affect the way the users accomplish their requests (e.g. connect to a collection in the Digital Library or request information about the collection). The final 359,157 analyzed operations belong to 60,869 sessions. 


\section{Operations Distribution}

The distribution of the performed operations for the eight selected collections, according to their functionality and excluding the operations that do not affect the way the users accomplish their requests, as shown in fig. 2, showed that the users accomplish their requests using mainly the two basic operations: "search" (50\%) and "present" $(43 \%)$, to retrieve the documents. The users avoid extracting information about metadata indexing, using the "browse" operation (4\%). Finally, they very rarely use the "search history" operation (1\%) to combine or further refine their search results.

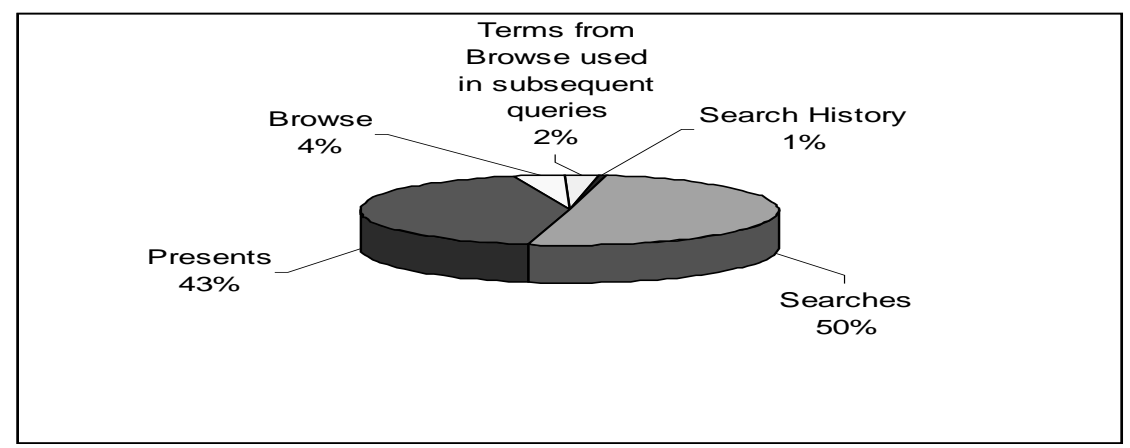

Fig. 2. Operation Distribution

The evaluation of the "search" operation usage and formulation showed that the majority $(81.51 \%)$ of the logged search operations were formulated using only one search term. A small number of "search" operations were formulated using more than one search terms combined by Boolean operators $(18.49 \%)$ of which a tiny portion $(0.1 \%)$ were also formulated reusing previously issued result sets.

The conclusion from the distribution of the operations in the session is that the users accomplish their requests using simply the basic operations, avoiding making use of advanced (complicated but more efficient at the same time) querying techniques.

\section{Evaluation of the Usage of Access Points}

For the four most commonly used Access Points, Table 1 shows the order of preference and the percentage of times each Access Point has been used, for each collection and all collections together.

The evaluation of the usage of Access Points, shows that the most commonly used Access Points, for all the collections in the Digital Library, are the "Any", "Author", "Title", "Subject Heading" (Table 1), from the seventeen ones used in the metadata (the used terminology for naming Access Points is the one used by the Z39.50 attribute set bib-1), mostly in this order.

The vast majority of all users, independent of user group, used the "Any" Access Point for almost all collections. The only exception occurs at collection C6, were the 
most used Access Point is the "Author" which could be explained from the specialized subject area of the collection's content (Archaeological Records with detailed metadata description, where scientific work is known and searched usually by author) in combination with the specific type of its closed targeted user group's requests.

Another interesting observation with regard to the first two categories of the collections is the big usage difference between the two most used Access Points. These collections consist of content with simple metadata structure and are targeted to a number of diverse types of occasional users.

The third category, consists of collections with typical library material (e.g. more complex metadata structure, diverse kinds of material) that usually impose a more accurate process by professionals with consequence a better quality of metadata. It is targeted to a more specific user group, and this explains why there is a balance between the three most used Access Points.

The most balanced usage between the commonly used Access Points, happens at the forth category, which consists of collections with common characteristics as those in the third category and targeted to librarians.

Consequently, we observe that the usage of these commonly used Access Points depends mainly on the collection they belong to as well as on the user group type they are targeted to.

Table 1. Summary of Access Points use per Collection

\begin{tabular}{|l|l|l|l|l|l|l|l|l|l|}
\hline AP & Total & C1 & C2 & C3 & C4 & C5 & C6 & C7 & C8 \\
\hline Any & $\begin{array}{l}110,120 \\
50.5 \%\end{array}$ & $51 \%$ & $57 \%$ & $78 \%$ & $67 \%$ & $39 \%$ & $30 \%$ & $30 \%$ & $35 \%$ \\
\hline Author & $\begin{array}{l}42,020 \\
19.3 \%\end{array}$ & $20 \%$ & $9 \%$ & $5 \%$ & $8 \%$ & $28 \%$ & $36 \%$ & $23 \%$ & $26 \%$ \\
\hline Title & $\begin{array}{l}34,911 \\
16 \%\end{array}$ & $13 \%$ & $22 \%$ & $10 \%$ & $17 \%$ & $26 \%$ & $26 \%$ & $21 \%$ & $18 \%$ \\
\hline $\begin{array}{l}\text { Subject } \\
\text { Heading }\end{array}$ & $\begin{array}{l}20,871 \\
9.5 \%\end{array}$ & $10 \%$ & $7 \%$ & $4 \%$ & $5 \%$ & $4 \%$ & $5 \%$ & $22 \%$ & $15 \%$ \\
\hline & $\begin{array}{l}\text { Any } \\
\text { Auth } \\
\text { or } \\
\text { Title } \\
\text { Sub- } \\
\text { ject }\end{array}$ & $\begin{array}{l}\text { Any } \\
\text { Tittle } \\
\text { Autho } \\
\text { Sub- }\end{array}$ & $\begin{array}{l}\text { Sub } \\
\text { ject }\end{array}$ & $\begin{array}{l}\text { Any } \\
\text { Title } \\
\text { Author } \\
\text { Sub- } \\
\text { ject }\end{array}$ & $\begin{array}{l}\text { Any } \\
\text { Title } \\
\text { Auth } \\
\text { or } \\
\text { Sub- } \\
\text { ject }\end{array}$ & $\begin{array}{l}\text { Any } \\
\text { Author } \\
\text { Title } \\
\text { Subject }\end{array}$ & $\begin{array}{l}\text { Author } \\
\text { Any } \\
\text { Title } \\
\text { Sub- } \\
\text { ject }\end{array}$ & $\begin{array}{l}\text { Any } \\
\text { Auth } \\
\text { or } \\
\text { Sub- } \\
\text { ject } \\
\text { Title }\end{array}$ & $\begin{array}{l}\text { Any } \\
\text { Auth } \\
\text { or } \\
\text { Title } \\
\text { Sub- } \\
\text { ject }\end{array}$ \\
\hline
\end{tabular}

When formulating a "search" operation, the user can specify the structure of the search term (e.g. word, words, phrase) and possibly use right or left truncation for each Access Point. The study of the most commonly used Access Point's structure used by the users to accomplish their search operations shows that, for almost all collections, the vast majority use the "Word" structure combined with the "Right Truncation" for the "Any" and "Title" Access Points and the "Phrase" structure combined also with the "Right Truncation" for the "Author" and "Subject Heading" Access Points. From the wide use of the right truncation we suspect that the majority of users are not very specific when expressing their requests accepting in most cases the system defaults.

Table 2 displays the usage of Access Point combinations for each collection and all collections together. We first observe that the Access Point "Any" is not that domi- 
nant in Access Point combinations as it was in single Access Point specifications. We also observe that the difference between the two most used Access Point combinations follows the previously observed Access Point usage pattern. Finally, for the majority of the collections, the most commonly used combination of Access Points is the "Title-Any", except for the collections C5, C6, C8. We have already seen (Table 1) that these collections have a more uniform usage on their single Access Points, without overusing the "Any" Access Point, and consequently the most commonly used combination of Access Points for them is the "Title-Author".

We also observe that the Access Point "Title" is used much more often on Access Point combinations, although it is the third one in the list of the most used Access Points, which indicate that "Title" is used in more sophisticated "search" operations and by more sophisticated users.

Table 2. Summary of Access Points Combination use per Collection

\begin{tabular}{|c|c|c|c|c|c|c|c|c|c|}
\hline & Total & $\mathrm{C} 1$ & $\mathrm{C} 2$ & C3 & $\mathrm{C} 4$ & C5 & C6 & C7 & $\mathrm{C} 8$ \\
\hline Title - Any & $\begin{array}{l}4,153 \\
30.6 \%\end{array}$ & $30 \%$ & $28 \%$ & $52 \%$ & $59 \%$ & $16 \%$ & $21 \%$ & $33 \%$ & $16 \%$ \\
\hline Title - Author & $\begin{array}{l}2,782 \\
20.5 \%\end{array}$ & $12 \%$ & $13 \%$ & $8.7 \%$ & $5 \%$ & $58 \%$ & $48 \%$ & $26 \%$ & $27 \%$ \\
\hline Author - Any & $\begin{array}{l}1,370 \\
10.1 \%\end{array}$ & $13 \%$ & $10 \%$ & $8.4 \%$ & $4 \%$ & $6 \%$ & $10.6 \%$ & $4.8 \%$ & $10 \%$ \\
\hline $\begin{array}{l}\text { Subject Heading - } \\
\text { Any }\end{array}$ & $\begin{array}{l}939 \\
6.9 \%\end{array}$ & $8.2 \%$ & $8 \%$ & $7 \%$ & $6 \%$ & $2.9 \%$ & $3.3 \%$ & $7.1 \%$ & $7 \%$ \\
\hline $\begin{array}{ll}\text { Title - Subject } \\
\text { Heading }\end{array}$ & $\begin{array}{l}561 \\
4.1 \%\end{array}$ & $4.3 \%$ & $5 \%$ & $2.6 \%$ & $2 \%$ & $2.1 \%$ & $3.1 \%$ & $6 \%$ & $6 \%$ \\
\hline $\begin{array}{l}\text { Title - Author - } \\
\text { Any }\end{array}$ & $\begin{array}{l}491 \\
3.6 \%\end{array}$ & $4.4 \%$ & $4 \%$ & $3.1 \%$ & $3 \%$ & $1.9 \%$ & $2.6 \%$ & $1.3 \%$ & $4 \%$ \\
\hline $\begin{array}{l}\text { Subject Heading - } \\
\text { Author }\end{array}$ & $\begin{array}{l}482 \\
3.5 \%\end{array}$ & $4 \%$ & $2 \%$ & $1.7 \%$ & $1 \%$ & $2 \%$ & $2.5 \%$ & $5.4 \%$ & $6 \%$ \\
\hline
\end{tabular}

Considering the results that, the vast majority $(81.51 \%)$ of the search queries consist of one search term and most users for almost all collections use a general Access Point, "Any", truncated to accomplish their requests with big usage difference from the next, more specific, Access Point, "Author" or "Title", we can infer that new users will need more operations to accomplish their requests which impacts the increase of the number of operations per session when new users enter the system.

\section{User Behavior (How a User Accomplishes the Job)}

Fig. 3 shows on a monthly basis the average operations per session and the number of sessions (scaled down to be shown together - its actual scale is not important and is not shown) aggregated for all eight collections studied. Similar lines correspond to each one of the studied collections.

The average number of operations per session (fig. 3) in general drops during the study period, while the number of sessions increases. Also, in August that most of the regular users are on their summer vacations, we have a smaller number of sessions, which indicates that we may have a lot of new users. Do the August data imply that new users need more operations per session to expresses their requests? 


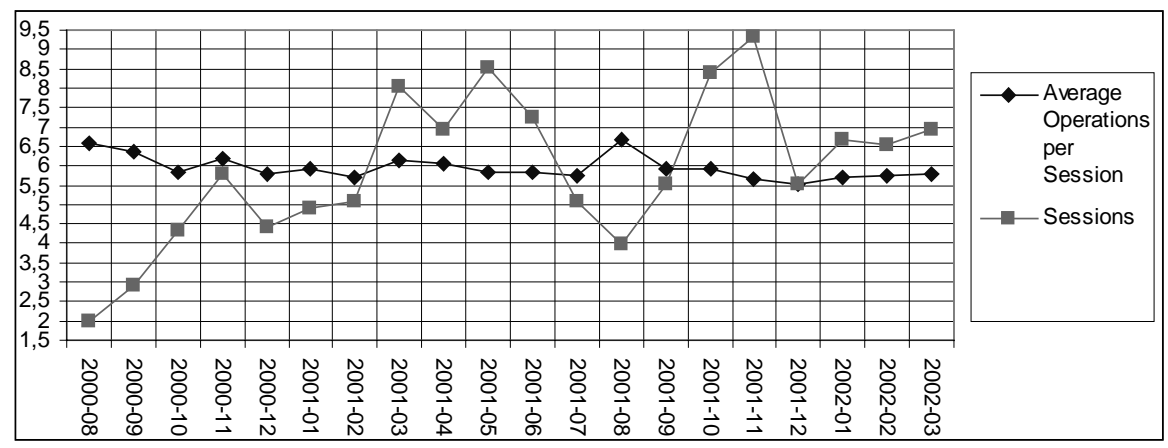

Fig. 3. Average Operations per session, Sessions

Fig. 4 shows the monthly proportion of sessions with operations less than or equal to three per session for three collections and aggregated for all eight collections studied, on a monthly basis. Similar lines correspond to the rest of the studied collections.

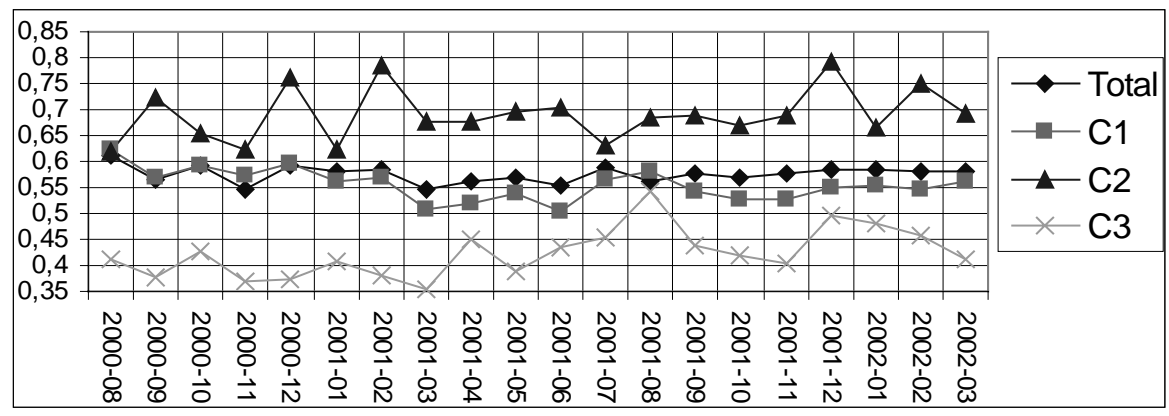

Fig. 4. Proportion of Sessions with less than or equal to 3 operations per session

We observe that in each month (Fig. 4), three operations are enough to fulfill at least half of the sessions in almost all collections - and the number of operations to fulfill at least half of the sessions on a specific collection depends on the collection. Furthermore, the number of sessions in each collection with less than or equal to three operations per session have a generally constant fluctuation, which indicates that a balance on the number of sessions with the same number of operations per session is maintained, from the new users that are added and the old users that become more experienced. We also see a slight increase to the proportion of sessions with less than or equal to 3 operations per session for the collections with mainly a closed set of users.

Please note that although the fact that only so few operations per session are enough to fulfill at least half of the sessions seem incompatible with the fact that the average number of operations per session is greater than 5 (Fig. 3), they can be explained by the existence of some sessions with a lot of operations, probably generated by some non-interactive query mechanism.

Another interesting question is how we measure the experience of the users. The experience of a specific user will certainly increase by time, but how can we distin- 
guish it from that of a newer user, on a system that does not record the identification of the user? Are there patterns on his behavior that are related to his experience?

We assume that one aspect of the experience of the user is measured by the number of operations that are included in a session, the full sequence of operations that the user performed. We have already concluded that most users perform few operations in order to find their material, but as the users become more experienced, do they use more operations (been able to make more complex sessions) or less operations (been more specific and efficient) in their sessions? The addition of new users into the system makes the distinction more difficult.

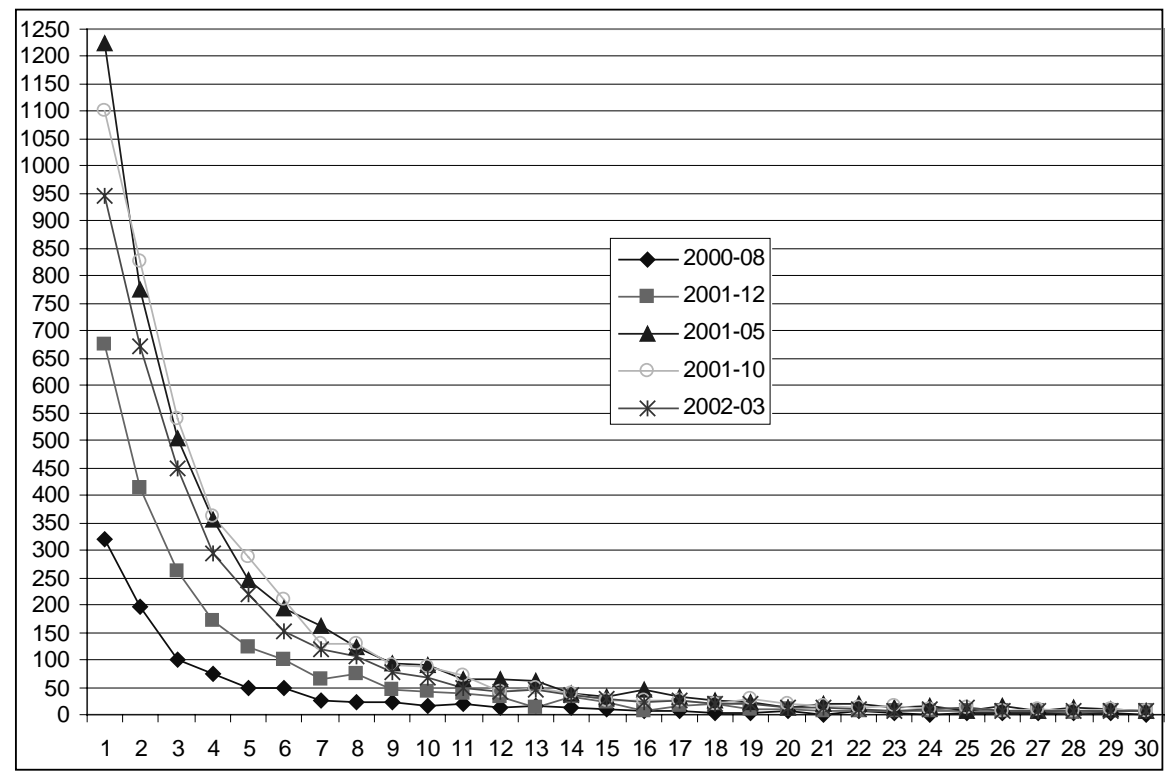

Fig. 5. Number of operations per session - Number of Sessions

Fig. 5 shows the number of sessions for each number of operations (from 1 to 30) per session for five representative months, aggregated for all collections. From fig. 5 we can see that on the later stages in our Digital Library lifetime, the increased number of users corresponds to only an increase to the number of sessions that have only one operation. We already observed, on the evaluation of Access Point usage, that new users perform queries with many operations per session. We also believe that it is unlikely that all new users perform only queries with one operation per session, and we can see from fig. 1 that the total number of sessions in the last three of the depicted months are practically the same, so we conclude that older users decrease the number of operations into their sessions, in a way that (by coincidence) corresponds to or outperforms the increase of new users performing the same number of operations per session. Thus expert users use fewer operations per session than non-expert users and the users decrease the number of operations in their sessions during the time they use the Digital Library. 
In fig. 6 we depict the number of sessions and operations for two collections on a monthly basis, where the number of operations has been divided by five, to be shown on the same scale. Other collections give similar results. Fig. 1 depicts the same quantities, aggregated for all collections.

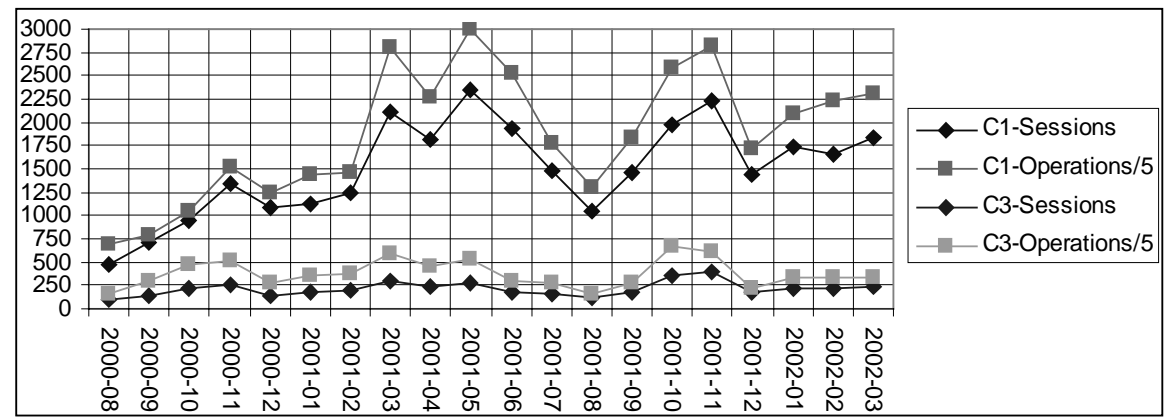

Fig. 6. Number of Sessions and Operations/5 per month for Collections C1, C3

We can see that the number of sessions follows proportionally the number of operations. We observe that on the months that have a steep increase on the number of sessions, the number of operations increases much faster, indicating that we have many new non-expert users, with many operations per session.

The reverse observation is in August, where the regular expert users are on their summer vacation, we have a big decrease on the number of sessions and the number of operations also decreases even more.

\section{Conclusions and Future Research}

We studied the differences on the usage among data collections and the way users accomplish their requests. We examined the relationship between the number of operations and sessions, and the distribution of the different types of operations, and we found that most users tend to use simple query structures and very few and primitive operations to accomplish their requests. We explored the usage count of the different access points and their combinations and we realized that they depend heavily on the type of the content of the collection, the detail of the existing metadata and the target user group, where the more sophisticated users use more complex structures and more specialized and informative access points. Finally, we investigated the evolution of the user behavior by the time, and we concluded that the users reduce the number of operations in their sessions, as they get more experienced.

From this work a number of interesting points arrives for future evaluation and research. A more detailed analysis for the search term formulation (e.g. word, phrase, truncation) used by a specific group of users to accomplish their search requests per collection would be interesting. Another point of interest is how different user types (e.g. professionals, ordinary users) behave under the same circumstances. What sequences (patterns) of operations (i.e. number of "Presents" follows the "Search" operation, etc.) in sessions do different types of users adopt? Finally, another interesting point of evaluation is the evolution of the query formulation complexity. 


\section{References}

1. ANSI/NISO: Z39.50 Information Retrieval: application service definition and protocol specification: approved May 10, 1995.

2. E. Fox, Robert Hall, Neill A. Kipp, John L. Eaton, Gail McMillan, and Paul Mather. NDLTD: Encouraging International Collaboration in the Academy. In Special Issue on Digital Libraries, DESIDOC Bulletin of Information Technology, 17(6): 45-56, Nov. 1997.

3. Bains S., "End-User Searching Behavior: Considering Methodologies", The Katharine Sharp Review, No. 4, Winter 1997.

4. Covey, D. T., "Usage and Usability Assessment: Library Practices and Concerns", Washington, D.C., Digital Library Federation Council on Library and Information Resources, January 2002, ISBN 1-887334-89-0.

5. Jones, S., Cunningham, S. J., McNab, R. J. and Boddie, S., "A Transaction log Analysis of a digital library", International Journal on Digital Libraries, v. 3:no. 2 (2000), pp. 152-169.

6. Larsen, Ronald L., "The DLib Test Suite and Metrics Working Group: Harvesting the experience from the Digital Library Initiative". D-Lib Working Group on Digital Library Metrics Website, April 2002.

7. Mahoui, M., Cunningham, S. J., "Search Behavior in a Research-Oriented Digital Library”, ECDL 2001, LNCS 2163, pp. 13-24.

8. Mahoui, M., Cunningham, S. J., "A Comparative Log Analysis of Two Computing Collections", Research and Advanced Technology for Digital Libraries: Proceedings of the $4^{\text {th }}$ European Conference, ECDL Lisbon, Portugal, Sept. 2000, pp. 418-423.

9. Peterson Bishop, A., "Working toward an understanding of digital library use: a report on the user research efforts of the NSF/ARPA/NASA DLI projects", D-Lib Magazine, October 1995.

10. Payette, S.D. and Rieger, O.Y. "Z39.50 The User's Perspective”, D-Lib Magazine, April 1997.

11. Sfakakis, M. and Kapidakis, S, "Evaluating User Behavior on Data Collections in a Digital Library", Forth DELOS Workshop on Evaluation of Digital Libraries: Testbeds, Measurements and Metrics, Budapest, Hungary, June 2002.

12. Van House, N.A. et. al., "User centered iterative design for digital libraries: the Cypress experience", D-Lib Magazine, February 1996. 